PESHAWAR JOURNAL OF PSYCHOLOGY AND BEHAVIORAL SCIENCES, 2017, VOL. 3, NO. 2, 189-203

\title{
Relationship of Peer Victimization, Psychological Distress and Self Esteem among Teenagers
}

\author{
Ruqia Safdar Bajwa $^{1}$, Kiran Firdous ${ }^{2}$, Iram Batool ${ }^{3}$ \\ Bahauddin Zakariya University Multan
}

\author{
Muhammad Imdad Ullah ${ }^{4}$ \\ Government College University Faisalabad
}

This study was designed to estimate the relationship of peer victimization, psychological distress and self-esteem among teenagers. The sample consisted of 233 teenager's age range from 11 to 20 years. Data was collected from Kot Addu and Multan District. Convenient Sampling method was used to collect the data. Illinois Bully scale developed by (Espelage, D. L. \& Holt, 2001) consisted of 18 items was used to check the rate of Peer Victimization. A 20 item state Self Esteem scale developed by (Heatherton, T. F. \& Polivy, 1991) was taken to check the level of self-esteem among teenagers. Another 10 item Kessler psychological Distress scale (K10) developed by (Kessler \& Mroczek, 1992) was used to check the level of distress among teenagers. The results were analyzed through SPSS. The findings of the study show that peer victimization leads to psychological distress and victimized teenagers have low level of self-esteem. It was also found that rate of peer victimization is high among school going teenagers as compared to college or university. Result further exposed that there is no significance difference in peer victimization on the basis of demographic variables like age group, gender, parent's qualification, no of siblings and family system.

\footnotetext{
${ }^{1}$ Lecturer, Department of Applied Psychology Bahauddin Zakariya University Multan

${ }^{2}$ M.Phil Scholar, Department of Applied Psychology Bahauddin Zakariya University Multan

${ }^{3}$ Assistant Professor, Department of Applied Psychology Bahauddin Zakariya University Multan, Corresponding author( i.batool@bzu.edu.pk)

${ }^{4}$ Assistant Professor, Government College University Faisalabad
} 
Keywords: peer victimization, psychological distress, and self esteem

The term peer victimization alludes to somebody - for the most part a kid - being the objective of peers' aggression. Aggressive behavior can be either obvious overt e.g., hitting, provoking or relational e.g., barring from gatherings or spreading tattle (Card, N. A.\& Stucky,2008) and incorporates practices famously alluded to as bullying. Moreover, the attention here is on exploitation from peers, or those of a comparative age. Peer Victimization alludes to the experience among offspring of being an objective of the forceful conduct of other kids, who are not kin and not really age-mates (Hawker \&Boulton, 2000, p.441). Victimization done by parents, siblings, or other adults is not considered efforts. Peer victimization is common among school children. In this regard Herrero, et al. (2005) conducted a research on Deviant behavior and victimization at school and claimed that it has been consistently associated to poor psychological adjustment among adolescents. Results indicate that adolescent's deviant behavior and victimization were positively lined to psychological distress as seen by the total effects; on the other hand victimization was directly linked to psychological distress. Peer victimization also associated with a variety of psychological, academic, social, and family factors (Card, et al., 2007).

Large samples of schoolchildren of South Australia of ten years of age and over were tested for the estimation of age and gender distribution of victimization (Rigby 1994a). When an anonymous questionnaire is used, boys as compared to girls are more expected to give information about their bullying experience. In primary schools with consecutive years of attendance victimization tends to decrease and it considerably increases in high school. These findings are consistent with the results of the national Kids Line phone-in service in 1993. It was concluded that peer victimization peaked at the age of thirteen. Many current investigations have found a very significant impact of peer victimization on the wellbeing of children. Victimized children were found with low level of self-esteem, high in depression, poor and reduced general health, socially lonely and segregated and more frequently remain absent from school with frequent suicidal thoughts (Rigby 1994b, Farrington 1993; Olweus 1993; Estevez, Herrero, Martínez, \& Musitu, 
2006). Low self-regard, anxiousness, and personality related problems could be a consequence of victimization (Egan \& Perry, 1998; Olweus, 1978; Graham \&Juvonen, 1998).

Physical complaints and psychosocial maladjustment are some evident health consequences of peer victimization (Arseneault et al, 2010; Bond et al, 2001; Due et al, 2005; Fekkes, 2004; Gini, 2008). Williams and co-workers (1996) concluded that higher occurrence of victimization lead to serious health threats (Rosen et al, 2009). Disproportionate use of power and repetitive aggressive behaviour refers to Bullying (Olweus, 1993; Smith, Brain, 2000). Vast variation was found in bullying and peer victimization, self-reporting was also found very common school children, different causes, consequences, and correlates of victimization were also investigated (Smith, 2004; Gini, Pozzoli, 2009; Hodges \& Perry, 1996; ). Alarming outcomes of peer victimization, for victims were identified as difficulties in social adjustment, submissive-withdrawn behaviours (Kochenderfer-Ladd, 2004; Fox \&Boulton, 2006; Boulton, 1999).

Previously it was found that peer victimization has strong link with children's emotional adjustment and depression and anxiety were considered as strong indicator as its impact (Franke\&Hymel, 1984; Kovacs, 1985; Parker \& Asher, 1987). Olweus's investigations (1991) concluded that overt aggressions among teen agers were associated with depression. In the same lines, Neary and Joseph (1994) explored the same association among girls and Slee (1995) found positive association across both genders.

Self-esteem is an individual judgment of the value that is communicated in the states of mind the individual holds towards himself. In this manner, Self-esteem is a state of mind about the self and is identified with individual convictions about aptitudes, capacities, social connections and future results (Cooper,1967). A previous investigation has found negative correlation between self-esteem and peer victimization, it was concluded that teenagers with low self-esteemed are frequently victimized than are adolescents with high self-esteem (Egan \& Perry, 1998; Grills \& Ollen-dick, 2002). A common reason for this association could be that adolescents who low self-esteem draw negative attention from peers, and might be they provoked particular bullying behaviours from their peer groups (Kaltiala-Heino, Rimpelä, Marttunen, Rimpelä, \& Rantanen, 1999; Olweus, 1992). Self-criticizing behaviours might be worked as an invitation to bullying behaviours from others (Egan \& Perry, 1998). And Hodges \& Perry, 1999 furthers concluded that 
adolescents with low self-esteem have less capability of counter-attacks. Results of their longitudinal studies mainly focused on self-esteem and victimization in children, and found that peer victimization and low selfesteem operate as mutually reinforcing systems.

Keeping in view the same notion in mind, the present study was carried out in order to determine relationship between peer victimization, psychological distress and self-esteem among teenagers from 11 to 20 year and also investigate the differences in age group, gender, no of siblings, parent's qualifications, family system and educational institutes on peer victimization in Pakistani context.

\section{Objectives}

1. To investigate the association between peer victimization and psychological distress among teenagers

2. To know the effect of peer victimization on self esteem of the teenagers.

3. To probe into the demographic factors (age, gender, family system, parental literacy, and number of siblings) effecting peer victimization among teenagers

\section{Hypotheses}

1. Peer victimization will be positively correlated with psychological distress.

2. Victimized teenagers have low level of self-esteem as compared to non-victimized

3. Males are more victimized as compared to female

4. The rate of peer victimization is high among early teenagers as compared to late teenagers

5. The rate of peer victimization is high in teenagers who live in nuclear family as compared to those who live in joint family system

6. The rate of peer victimization is low in teenagers whose parents are literate as compared to those whose parents are illiterate

7. The rate of peer victimization will high in teenagers who are single child, having no sibling or age mate as compared to those who have two or more siblings 


\section{Method}

\section{Sample}

The sample comprised of 233 teenagers ( 73 Male 160 Female) studying in different school, college and university ranging in age from 11- 20 years. Convenience sampling was used to select participants from different school, college and university from different area of KotAddu and Multan.

\section{Tools}

Along with the instrument a demographic sheet is attached in order to know about the demographic variable. The required information was age, gender, No of siblings, education, parent's qualification, family system. Following three instruments were used in this research.

- State Self Esteem Scale developed by (Heatherton, T. F. \& Polivy, 1991). Development and validation of a scale for measuring state self esteem Journal of Personality and Social Psychology, 60, 895-910. )

- Kessler psychological Distress scale(K10) developed by (Kessler, R.C., Andrews, G., Colpe, .et al ,2002) Short screening scales to monitor population prevalences and trends in non-specific psychological distress Psychological Medicine, 32 959-956.

- Illinois Bully scale developed by (Espelage, D. L. \& Holt, M, 2001). Bullying and victimization during early adolescence: Peer influences and psychosocial correlates. Journal of Emotional Abuse, 2, 123-14)

\section{Procedure}

The participants were approached individually and collected data from them. They were briefed about the nature of research being carried out. Their consent and cooperation was required and after their permission and willingness. The questionnaire was handed over to them state self-esteem scale, psychological distress scale and bully scale and asked them to select the option which are truly representative of their choice. It was also clear to them that the information collected from them would be kept confidential and will be used only for research purpose. The SPSS statistical package was used to analyze the data ANOVA, $t$ test correlation, one-way ANOVA and Means were used for statistical analysis of data. 


\section{Results}

The present study aimed at exploring the relationship between peer victimization, psychological distress and self-esteem among teenagers. The result were analyzed, concluded and interpreted using SPSS (statistical package for social science).

Table 1

Matrix of Pearson Correlation Coefficient of Peer Victimization and Psychological Distress

\begin{tabular}{ccccc}
\hline Predictor & & SD & BS & PDS \\
\hline BS & 33.59 & 13.08 & - & \\
PDS & 24.69 & 5.84 & $.21^{* *}(.001)$ & -
\end{tabular}

Note: **correlation is significant at the 0.01level (2-tailed); $B S=$ bully scale; $P D S=$ psychological distress scale

Table 1 shows Pearson product moment-correlation coefficient among peer victimization and psychological distress. Victimization has positively correlated with the psychological distress and there is significant relation between these two variables. $r=0.001, \mathrm{p}<0.01$.

Table 2

Regression Analysis Between Peer Victimization and Psychological Distress

\begin{tabular}{llllll}
\hline Predictor & \multicolumn{1}{c}{$\mathrm{B}$} & \multicolumn{1}{c}{ Std. Error } & \multicolumn{1}{c}{ Beta } & $\mathrm{T}$ & $p$ \\
\hline Constant & 21.48 & 1.03 & & 20.77 & .001 \\
PDS & .09 & .02 & .21 & 3.33 & .001 \\
\hline Note: $R^{2}=.04$, adjusted & $R^{2}=.042,(F(1,231)=11.127, p<=0.01)^{*} p<=0.01 ;$ \\
$P D S=$ psychological distress scale. & & &
\end{tabular}

Table 2 shows the regression analysis by taking psychological distress as dependent variable, which depend on peer victimization. Table shows co-efficient multiple determination $\mathrm{R}^{2}(.046)$ and adjust $\left.\mathrm{R}^{2} .042\right)$.It also indicate analysis of variance of teenagers whereas psychological distress is a dependent variable which depends on victimization $F(1,231)$, $\mathrm{p}<0.05$. More over table represent significant regression co-efficient, $\mathrm{t}=3.33$. The result showed peer victimization leads to psychological distress among teenagers.

PESHAWAR JOURNAL OF PSYCHOLOGY AND BEHAVIORAL SCIENCES, 2017, VOL. 3, NO. 2, 189-203 
Table 3

Matrix of Pearson Correlation Coefficient of Peer Victimization and SelfEsteem

\begin{tabular}{lllll}
\hline Predictor & M & SD & BS & SES \\
\hline BS & 33.59 & 13.08 & - & - \\
SES & 69.84 & 9.62 & $-.42 * *(.001)$ & - \\
Note: $* *$ correlation is significant at the 0.01 level (2-tailed); BS=bully scale; \\
SES= self-esteem scale
\end{tabular}

Table 3 shows Pearson product moment-correlation coefficient among peer victimization and self-esteem. The result also shows that there is a positive relation between peer victimization and self-esteem and there is significant relation between these two variables. $r=-.42, p<0.001$.

Table 4

Regression Analysis Between Peer Victimization and Self-Esteem

\begin{tabular}{lcllcc}
\hline Predictor & $\mathrm{B}$ & Std.Error & Beta & $\mathrm{t}$ & $p$ \\
\hline Constant & 80.40 & 1.57 & & 51.00 & .001 \\
SEQT & -0.31 & .04 & -.42 & -7.18 & .001 \\
\hline Note: $R^{2}=.18$, adjusted $R^{2}=.17,(F(1,231)=51.649, p<=0.001){ }^{*} p<=0.05$
\end{tabular}

Table 4 shows the regression analysis by taking self-esteem as dependent variable, which depend on peer victimization. Table shows coefficient multiple determination $\mathrm{R}^{2}(.18)$ and adjust $\mathrm{R}^{2}$.17). It also indicates analysis of variance of teenagers whereas self-esteem is a dependent variable which depends on victimization $F(1,231), p<0.05$. More over table represent significant regression co-efficient, $t=-7.18$. The result showed peer victimization leads to low level of self-esteem among teenagers. 
Table 5

Mean Standard Deviation, t-Value of Victimization Between Male and Female $(N=233)$

\begin{tabular}{lllllll}
\hline Groups & $\mathrm{N}$ & Mean & $\mathrm{SD}$ & $\begin{array}{l}\text { S.error } \\
\text { Mean }\end{array}$ & $\mathrm{t}$ & $\mathrm{P}$ \\
\hline Male & 76 & 36.00 & 13.69 & 1.57 & 1.96 & .05 \\
Female & 157 & 32.43 & 12.66 & 1.01 & 1.91 & .05 \\
\hline
\end{tabular}

Note: $d f=233, p>0.05$

Table 5 indicates the rate of peer victimization on the basis of gender differences. The average mean of male on victimization is (36.00) with standard deviation of (13.69) and for male the mean score is (32.43) with standard deviation of (12.66). Independent sample $t$ test has been applied. The result reveals that there is no significance difference in peer victimization among male and female teenagers.

Table 6

Mean Standard Deviation, $t$-Value of Victimization Between Early and Late Teenagers $(N=233)$

\begin{tabular}{lccclcc}
\hline Groups & $\mathrm{N}$ & Mean & $\mathrm{SD}$ & $\begin{array}{l}\text { S.error } \\
\text { Mean }\end{array}$ & $\mathrm{T}$ & $\mathrm{P}$ \\
\hline Early teens & 22 & 31.90 & 11.53 & 2.45 & 0.58 & .55 \\
Late teens & 210 & 33.60 & 13.05 & 0.90 & 0.64 & .52 \\
\hline Note: $d f=232, p>0$ & & & & &
\end{tabular}

Table 6 indicates the rate of peer victimization on the basis of age differences. The average mean of early teenagers on victimization is (31.90) with standard deviation of (11.53) and for late teenagers the mean score is (33.60) with standard deviation of (13.05). Independent sample $t$ test has been applied. The result reveals that there is no significance difference in peer victimization on the basis of age differences. 
Table 7

Mean Standard Deviation, $t$-value of Victimization Between Nuclear and Joint Family System (N=233)

\begin{tabular}{lcccccc}
\hline Groups & $\mathrm{N}$ & Mean & $\mathrm{S} . \mathrm{D}$ & $\begin{array}{l}\text { S.error } \\
\text { Mean }\end{array}$ & $\mathrm{t}$ & $\mathrm{p}$ \\
\hline Nuclear & 166 & 32.66 & 12.61 & 0.97 & -1.722 & .086 \\
Joint & 67 & 35.91 & 14.01 & 1.71 & -1.647 & .102 \\
\hline Note: $d f=232, p>0.05$ & & & & &
\end{tabular}

Table 7 indicates the rate of peer victimization on the basis of family system. The average mean nuclear family on victimization is (32.66) with standard deviation of (12.61) and joint family the mean score is (35.91) with standard deviation of (14.01). Independent sample t test has been applied. The result reveals that there is no significance difference in peer victimization on the basis of family system.

Table 8

Mean Standard Deviation, $t$-value of Victimization Between Literate and Illiterate Parents $(n=203,30)$

\begin{tabular}{lllrlll}
\hline Groups & $\mathrm{N}$ & Mean & S.D & $\begin{array}{l}\text { S.error } \\
\text { Mean }\end{array}$ & $\mathrm{t}$ & $\mathrm{P}$ \\
\hline Literate & 203 & 33.80 & 13.12497 & .92 & .64 & .52 \\
Illiterate & 30 & 32.16 & 12.94307 & 2.36 & .64 & .52 \\
\hline
\end{tabular}

Note: $d f=232, p>0.05$

Table 8 indicates the rate of peer victimization on the basis of parent's qualification. The average mean of literate parents on victimization is (33.80) with standard deviation of (13.12) and for illiterate parents the mean score is (32.16) with standard deviation of (12.94). Independent sample $\mathrm{t}$ test has been applied. The result reveals that there is no significance difference in peer victimization on the basis parent's qualification. 
Table 9

Differences in Peer Victimization on the Basis of Number of Siblings

\begin{tabular}{lccccc}
\hline & SS & Df & MS & F & P \\
\hline Between group & 59.884 & 2 & 29.942 & 174 & .841 \\
Within group & 39666.193 & 230 & 172.46 & & \\
Total & 39726.07 & 232 & & &
\end{tabular}

Note: $S S=$ sum of square, $d f=$ degree of freedom, $M S=$ mean square,$F=$ frequency, $p=$ significant value

Table 9 reveals summary of analysis of variance (ANOVA) among victimization score of teenagers on the basis of no of siblings. It also indicates the sum of square and mean score of victimization $F$ (174). The result reveals that there is no significance in peer victimization on number of siblings.

Table 10

Differences in Peer Victimization among Educational Institute

\begin{tabular}{cccccc}
\hline & SS & Df & MS & F & P \\
\hline Between group & 1635.859 & 3 & 545.288 & 3.27 & $.022^{*}$ \\
Within group & 38090.218 & 229 & 554.717 & & \\
Total & 39726.07 & 232 & 166.33 & &
\end{tabular}

Note: $S S=$ sum of square, $d f=$ degree of freedom, $M S=$ mean square, $F=$ frequency, $p=$ significant value. ${ }^{*} p<=0.05$

Table 10 reveals summary of analysis of variance (ANOVA) among victimization score of teenagers on the basis of educational institute. It also indicates the sum of square and mean score of victimization $F$ 3.27. The result reveals that there is a significance difference in peer victimization on the basis of educational institute. The rate of peer victimization is high in school as compared to college and university.

\section{Discussion}

The statistical analysis of the data leads to the acceptance of the two main hypothesis of the research. But the statistical data confirms that there are no differences in victimization on the basis of demographic 
variable like gender, age group, family system, no of siblings and parents qualification. The first hypothesis stated that peer victimization will be positively correlated with psychological distress. Results also support this hypothesis that being a target of victimization leads to psychological distress among teenagers. According to previous research victimization is directly related to psychological distress. (J. Herrero et al). $\mathrm{P}<0.05$.Hence hypothesis is accepted.

The second hypothesis stated that victimized teenagers have low level of self-esteem as compared to non-victimized. Result also support this hypothesis that being a target of victim leads to low level self-esteem among teenager. As previous research revealed that PV predicted significant increases in negative views of the self, world, and future and decreases in self-perceived competence (Thomas, et al) $\mathrm{P}<0.05$. Hence hypothesis is accepted.

Third hypothesis stated that males are more victimized as compared to female. Result shows no significance differences in peer victimization on the basis of gender as in male $(\mathrm{p}<0.51)$ and in female $(p<0.58) p>0.05$, as the result shows that both girls and boys are equally victimized. One reason can be in present era in which both girls and boys have equal social interaction both are equally social so on the basis of this reason both are equally victimized. Hence hypothesis is rejected.

Fourth hypothesis stated that the rate of peer victimization is high among early teenagers as compared to late teenagers. Result also support this hypothesis as in early teenagers $(\mathrm{p}<.55)$ and in late teenagers $(\mathrm{p}<.52)$. $\mathrm{p}>0.05$ Hence hypothesis is rejected. The reason may be there is no significance difference in their ages.

Fifth hypothesis stated that the rate of peer victimization is high in teenagers who live in nuclear family as compared to those who live in joint family system. Result also don't support this hypothesis as in nuclear family $(p<.08)$ and in joint family $(p<.10) . p>0.05$ Hence hypothesis is rejected. One reason may be that family system does not influence the social life of teenagers.

Sixth hypothesis stated that the rate of peer victimization is low in teenagers whose parents are literate as compared to those whose parents are illiterate. Result also support this hypothesis as in literate parents $(\mathrm{p}<.52)$ and illiterate parents $(\mathrm{p}<.52) . \mathrm{p}>0.05$. Hence hypothesis is rejected. The reason can be that peer victimization among teenagers is not influenced by the qualification of the parents. Seventh hypothesis stated that the rate of peer victimization will high in teenagers who are single 
child, having no sibling or age mate as compared to those who have two or more siblings. Result also support this hypothesis as $(\mathrm{p}<.84) . \mathrm{p}>0.05$ Hence hypothesis is rejected. Eightieth hypothesis stated that the rate of peer victimization will high in teenagers who study in school as compared to those who study in college or university. Result also support this hypothesis as $(\mathrm{p}<.022)$. Because the reason is that school going teenagers are more victimized because of low level of maturity as they grow there maturity level increase and rate of peer victimization decrease with the passage of time. $p<0.05$, Hence hypothesis is accepted.

\section{Conclusions and Recommendation}

To sum up it can be concluded that peer victimization leads to psychological distress and victimized teenagers have low level of selfesteem. It was also found that rate of peer victimization is high among school going teenagers as compared to college or university. Result further reveals that there is no significance difference in peer victimization on the basis of demographic variables like age group, gender, parent's qualification, no of siblings and family system. In the light of the conclusions and the above mentioned discussion it was recommended that Sample size should be increased to increase external validity or generalizability of the finding of the research. More study should be conducted particularly in Pakistan to draw authentic conclusion. This study should be also done on different age group. In future the study should be conducted with interviews as well as scales. The concept of peer victimization, psychological distress and self-esteem is very broad; more work should be done on it to explore it more deeply. New researcher can explore their concept in more depth with new variation.

\section{References}

Arseneault L, Bowes L, \&Shakoor S, (2010). Bullying victimization in youths and mental health problems: Much ado about nothing? Psychol Med., 40 (05): 717-729. 10.1017/S0033291709991383.

Bond L, Carlin JB, Thomas L, Rubin K, \& Patton G, (2001). Does bullying cause emotional problems? A prospective study of youngteenagers.BMJ.323(7311):48048410.1136/bmj.323.7311.4 80 . 
Boulton\& M. J. (1999). Concurrent and longitudinal relations between children's playground behavior and social preference, victimization, and bullying. Child Development, 70, 944-954.

Card et al., (2007). Correlates of school victimization: Recommendations for prevention and intervention. In J. E. Zins, M. J. Elias, \& C. A. Maher (Eds.), Bullying, victimization, and peer harassment: A handbook of prevention and intervention (pp. 339-368). New York: Haworth Press.

Card et al., (2008). Direct and indirect aggression during childhood and adolescence: A meta-analytic review of gender differences, intercorrelations, and relations to maladjustment. Child Development, 79, 1185-1229.

Coopersmith\& S, (1967). The antecedents of self-esteem. San Francisco: Freeman.

Due P et al., (2005). Bullying and symptoms among school-aged children: International comparative cross sectional study in 28 countries. Eur J Public Health., 15 (2): 128-132. 10.1093/eurpub/cki105.

Egan, S. K., Perry \& D. G, (1998) Does low self-regard invite victimization? Developmental Psychology, 34(2), 299-309.

Espelage, D. L. \& Holt, (2001). Bullying and victimization during early adolescence: Peer influences and psychosocial correlates. Journal of Emotional Abuse, 2, 123-142

Estévez, E., Musitu, G., \&Herrero, (2005). the influence of violent behavior and victimization at school on psychological distress: the role of parents and teachers Adolescence, 40(157), 183-196.

Farrington \& D.P, (1993). 'Understanding and Preventing bullying', Crime and Justice, eds M. Tonry\& N. Morris, vol. 17, University of Chicago Press.

Fekkes M, Pijpers FI \& Verloove-Vanhorick SP, (2004). Bullying behavior and associations with psychosomatic complaints and depression in victims. J Pediatr. 144 (1): 17-22. 10.1016/j.jpeds.2003.09.025.

Fox, C. L., Boulton\& M. J, (2006). Friendship as a moderator of the relationship between social skills problems and peer victimization. Aggressive Behavior, 32,110-121.

Franke, S. \& Hymel, S, (1984). Social anxiety in children: The development of self-report measures. Paper presented at the biennial meeting of the University of Waterloo conference on child development, Waterloo, Ontario, Canada. 
Gini G \& Pozzoli T, (2009). Association between bullying and psychosomatic problems: A meta-analysis. Pediatrics, 123(3):1059-1065.

Gini G (2008). Associations between bullying behavior, psychosomatic complaints, emotional and behavioral problems. J Paediatr Child Health. 44 (9): 492-497. 10.1111/j.1440-1754.2007.01155.x.

Graham, S., \&Juvonen, J. (1998). Self-blame and peer victimization in middle school: An attributional analysis. Developmental Psychology, 34, 587-599.

Grills, A. E., Ollendick \& T. H, (2002). Peer victimization, global selfworth, and anxiety to middle school children. Journal of Clinical Child and Adolescent Psychology, 31, 59-68.

Hawker, D. S. J., \&Boulton, M. J, (2000). Twenty years' research on peer victimization and psychosocial maladjustment: a meta-analytic review of cross-sectional studies. Journal of Child Psychology and Psychiatry, 41, 441-455.

Heatherton et al., (1991). Development and validation of a scale for measuring state self esteem. Journal of Personality and Social Psychology, 60, 895-910.

Herrero, J., Estévez, E., and Musitu, G. (2005). Deviant behavior and victimization at school: exploring the role of parents and teachers in adolescent psychological distress. Journal of Adolescence 29, 671-690.

Hodges, E. V. E., \& Perry, D. G, (1999). Personal and interpersonal antecedents and consequences of victimization by peers. Journal of Personality and Social Psychology, 76, 677-685.

Hodges, E. V. E., \& Perry, D. G. (1996). Victims of peer abuse: an overview. Journal of Emotional and Behavioral Problems, 5, 23 28.

Kaltiala-Heino et al, (1999) Bullying, depression, and suicidal ideation in Finnish adolescents: School survey. British Medical Journal, 319, 348-351.

Kessler, R, Mroczek, \& D, (1992). An update of the development of mental health screening scales for the US national health interview study. Ann Arbor, MI: Survey Research Center of the Institute for Social Research. University of Michigan.

Kochenderfer-Ladd \& B, (2004). Peer victimization: the role of emotions in adaptive and maladaptive coping. Social Development, 13(3), 329-349.

PESHAWAR JOURNAL OF PSYCHOLOGY AND BEHAVIORAL SCIENCES, 2017, VOL. 3, NO. 2, 189-203 
Kovacs, M. (1985). The children's depression, inventory (CDI). Psychopharmacology Bulletin, 21,995-998.

Neary, A. \& Joseph, S, (1994). Peer victimization and its relationship to self-concept and depression among schoolgirls. Personality and Individual Differences, 16, 183-1 86.

Olweus\& D, (1991). Bully/victim problems among schoolchildren: Basic facts and effects of a school based intervention program. In D. (Pepler \& K. Rubin (Eds.), The development and treatment of childhood aggression (pp. 411448). Hillsdale, N.J.: Erlbaum.

Olweus D (1993). Bullying at school. What we know and what we can do. Oxford, U.K.: Blackwell.

Parker, J. Asher, S. (1987). Peer acceptance and later personal adjustment: Are low acceptance children at risk? Psychological Bulletin, 102, 357-389.

Rigby \& K, (1994a) 'School bullies', Independent Teacher, vol. 10, no. 2, pp. 8-9.

Rigby\& K, (1994b). 'Family influence, peer-relations and health effects among school children', Children's Peer/Relations Conference Proceedings, eds K. Oxenberry, K. Rigby \& P.T. Slee, The Institute of Social Research, University of South Australia, Adelaide, pp. 294-304.

Rosen L et al., (2009). Persistent versus periodic experiences of social victimization: Predictors of adjustment. J Abnorm Child Psychol, 37(5):693-704.

Slee\&P, (1995). Peer victimization and its relationship to depression among Australian primary school students. Personality and Individual Differences, 18, 57-62.

Smith PK \& Brain P, (2000). Bullying in schools: Lessons from two decades of research. Aggressive Behavior, 26(1):1-9.

Smith PK (2004). Bullying Recent Developments. Child Adolescent Mental Health, 9(3):98-103.

Thomas, S. et al., (2010). Child Development, Vol. 81, No. 3 MAY/JUNE 2010), pp. 811-825

Williams K, Chambers M, Logan S \& Robinson D, (1996). Association of common health symptoms with bullying in primary school children. BMJ., 313 7048: 17-19. 